\title{
CONCAVE SURFACE BASE-ISOLATION SYSTEM AGAINST SEISMIC POUNDING OF IRREGULAR ADJACENT BUILDINGS
}

\author{
FABIO MAZZA' ${ }^{1}$ AND RODOLFO LABERNARDA ${ }^{2}$ \\ ${ }^{1}$ Dipartimento di Ingegneria Civile, Università della Calabria, \\ 87036 Rende (CS), Italy \\ fabio.mazza@unical.it \\ ${ }^{2}$ Dipartimento di Ingegneria Civile, Università della Calabria, \\ 87036 Rende (CS), Italy \\ rodolfo.labernarda@unical.it
}

Key words: Seismic Pounding, Adjacent Structures, Base-Isolation, Sliding Bearings.

\begin{abstract}
The application of the concave surface sliders (CSSs) as seismic-isolation system of buildings is growing due to the automatic coincidence between the projection of the gravity mass centre of the superstructure and the stiffness centre of the CSSs, during the sliding phase, and self-re-centring properties, after an earthquake. These advantages make them attractive for the retrofitting of adjacent fixed-base framed buildings with irregular plan that may experience significant seismic pounding induced by torsional displacements. However, friction force and lateral stiffness of the CSSs present continuous variation during an earthquake because they are proportional to the axial load. Moreover, further changes of the friction force result from variation of the friction coefficient depending on the sliding velocity, with reduction at the onset of motion of the CSS and motion reversals, axial pressure and temperature at the sliding surface. In this work, structural pounding incidences are investigated with reference to five-storey reinforced concrete (r.c.) framed structures with an L-shaped plan placed adjacent to form Tand C-shaped plans. A simulated design of the original fixed-base buildings is preliminarily carried out in accordance to an old Italian code, for a medium-risk seismic zone and a typical subsoil class. Then, the seismic retrofitting of the residential buildings is carried out with the CSS bearings, for attaining performance levels imposed by current Italian code in a high-risk seismic zone and for moderately-soft subsoil. The design of the base-isolation systems is carried out on the assumption that the same radius of curvature is considered for all the isolators, with constant or variable dynamic-fast friction coefficients. A computer code for the nonlinear dynamic analysis of the fixed-base and base-isolated test structures is developed, in order to compare different models of the CSS bearings that consider constant and variable axial load combined with friction coefficient at breakaway and stick-slip and as function of the sliding velocity, axial pressure and temperature. The inelastic response of the superstructure is also taken into account by a lumped plasticity model at the end sections of r.c. frame members, where flat surface modelling of the axial load-biaxial bending moment elastic domain is adopted. Attention is focused on the pulse-type and non-pulse-type nature of near-fault earthquakes.
\end{abstract}




\section{INTRODUCTION}

The strong detrimental effects of pulse-type near-fault ground motions, characterized by high-amplitude and long-period velocity pulses, cause concern about the reliability of the baseisolation as retrofitting system for existing framed buildings [1]. Large displacement at the base, together with the amplification of inelastic demand of the superstructure, is generally expected for base-isolated structures in a near-fault area [2]. It is well known that velocity-pulses can be classified in terms of additional features, as those generated by a distinct acceleration pulse (AP) or a succession of high-frequency acceleration spikes (non-acceleration pulse, NAP), as reported in [3]. Concave surface sliders (CSSs) are considered an effective solution to eliminate the asymmetry between the projection of the gravity mass centre of the superstructure and the stiffness centre of the isolation system during the sliding phase, also ensuring self-re-centring after a seismic event [4]. This makes them attractive for retrofitting adjacent and fixed-base framed buildings irregular in plan that could undergo significant seismic pounding due to torsional displacements. Friction force and lateral stiffness of the CSSs are variable during an earthquake because of their dependence on axial load, sliding velocity (with reduction at the onset of motion of the CSS and motion reversals) and temperature at the sliding surface.

In this work, structural pounding is investigated with reference to five-storey reinforced concrete (r.c.) framed buildings, irregular in plan (L-shaped). Relative displacement between the fixed-base (original) and base-isolated (retrofitted) structures, placed adjacent to form Tand C-shaped plans, is evaluated considering the reciprocal positions of the facing sides. A

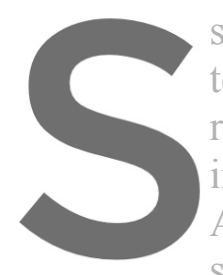
simulated design of the original fixed-base buil
to an old Italian code [5], for a medium-risk
residential buildings are retrofitted by means o
imposed by current Italian code [6] in a high-ri
A computer code [7] for the nonlinear dynamic structures is adopted, in order to compare two
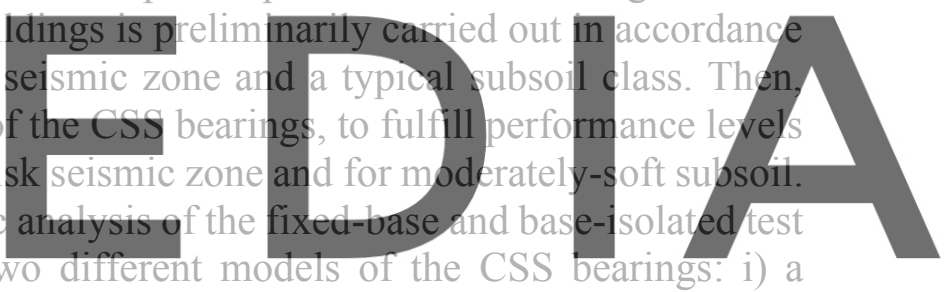
simplified model (FP1), with constant axial load and friction coefficient; ii) an advanced model

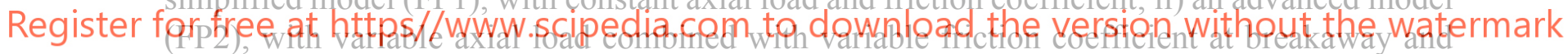

stick-slip phases and as function of the sliding velocity, axial pressure and temperature. The inelastic response of the superstructure is taken into account by a lumped plasticity model at the end sections of r.c. frame members, where a flat surface axial load-biaxial bending moment elastic domain is adopted. Attention is focused on the pulse-type and non-pulse-type nature of near-fault earthquakes, identifying potential pulses in the acceleration time-histories by means of an automated algorithm [8].

\section{DESIGN AND MODELLING OF FIXED-BASE AND BASE-ISOLATED TEST STRUCTURES}

A fixed-base five-storey L-shaped residential building (Figure 1) with r.c. framed structure, representative of a spread typology in Italy [9], is assumed as original structure for the numerical investigation. Bays of different length are responsible of the in-plan irregularity along both principal directions (Figure 1a); floor height is equal to $4.0 \mathrm{~m}$, for level 1, and 3.3 $\mathrm{m}$, for the other levels, with an overall height of $17.2 \mathrm{~m}$ (Figure 1b). One-way ribbed concrete slabs are supported by deep beams, while flat beams are placed parallel to the slab direction to complete the floor structure. 


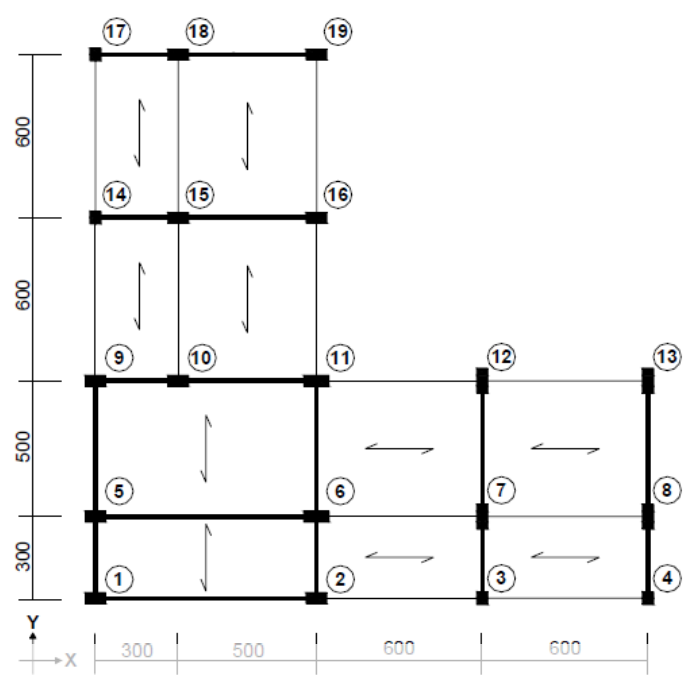

Plan (plane X-Y)

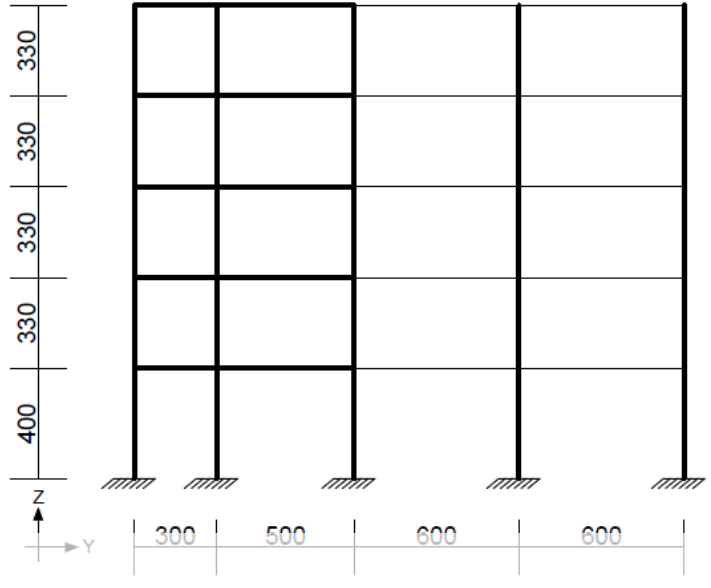

(b) Elevation (plane Y-Z)

Figure 1: Fixed-base (original) test structure (unit in $\mathrm{cm}$ )

A simulated design of the original framed building is performed, at the ultimate limit state, in accordance with an old Italian code [5], for medium-risk seismic region (seismic coefficient $C=0.07$; response coefficient $R=1$; structure coefficient $\beta=1$ ) and typical subsoil class

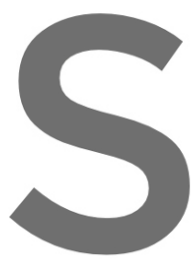
(foundation coefficient strength of $375 \mathrm{~N} / \mathrm{mnn}^{2}$ $\mathrm{kN} / \mathrm{m}^{2}$, for the top floor used for all levels with an additional sne only for the vertical lo elevation along the perimetc
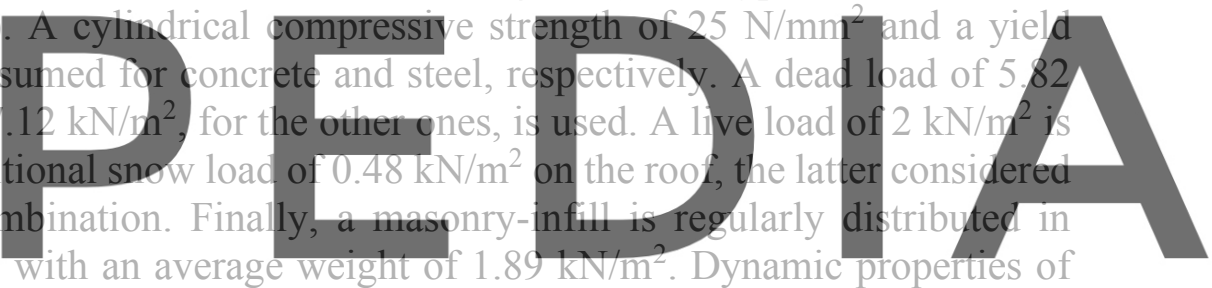
the five main vibration modes are reported in Table 1: i.e. vibration period. $(T)$; translational

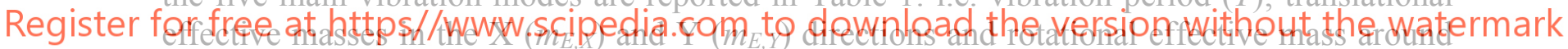
the $\mathrm{Z}$ direction $\left(m_{E, r} \mathrm{z}\right)$, expressed as a percentage of the total mass $\left(m_{t o t}\right)$. Details about cross sections of beams and columns can be found in [9].

Table 1: Dynamic properties of test structure $\left(\mathrm{m}_{\mathrm{tot}}=1626\right.$ ton $)$

\begin{tabular}{ccccc}
\hline Vibration mode & $\mathrm{T}(\mathrm{s})$ & $\mathrm{m}_{\mathrm{E}, \mathrm{X}}\left(\% \mathrm{~m}_{\mathrm{tot}}\right)$ & $\mathrm{m}_{\mathrm{E}, \mathrm{Y}}\left(\% \mathrm{~m}_{\text {tot }}\right)$ & $\mathrm{m}_{\mathrm{E}, \mathrm{rZ}}\left(\% \mathrm{~m}_{\text {tot }}\right)$ \\
\hline 1 & 0.918 & 9.60 & 45.70 & 5.53 \\
2 & 0.764 & 50.20 & 24.71 & 0.052 \\
3 & 0.633 & 20.22 & 10.03 & 74.82 \\
4 & 0.312 & 0.98 & 7.91 & 0.92 \\
5 & 0.262 & 8.68 & 2.88 & 0.00 \\
\hline
\end{tabular}

A base-isolation system constituted of nineteen CSS bearings is assumed for the seismic retrofitting of the original fixed-base building, attaining performance levels imposed by current Italian code [6] in a high-risk seismic zone (PGA on rock, $a_{g}=0.334 \mathrm{~g}$ at the CP limit state) and for moderately-soft subsoil (class C, site amplification factor $S=1.219$ ), neglecting the vertical component of the seismic load. The design of the isolation system is carried out on the assumption that the same radius of curvature $(R)$ is used for all the isolators, with an effective 
fundamental vibration period of the isolation system $\left(T_{i s o}=3.1 \mathrm{~s}\right)$ depending on spectral displacement at the CP limit state $\left(d_{d C}=25 \mathrm{~cm}\right)$. Further information can be found in [9].

The restoring force of a CSSB during the sliding phase contains pendular and friction components that can be evaluated by considering equation (1a), where $N$ is the axial load during an earthquake, $u_{X}$ and $u_{Y}$ represent the horizontal displacements, and a circular domain for biaxial interaction is used by considering the ratio between the hysteretic forces along $\mathrm{Y}$ and $\mathrm{X}$ direction $(\theta)$ (equation (1b)). A gap element with infinitely rigid behaviour in compression is assumed in the vertical direction (equation (1c)), in order to consider the reversal of the axial load from compression to tension depending on the vertical displacement $u_{V}$.

$$
\boldsymbol{F}_{H}=\left\{\begin{array}{l}
F_{x} \\
F_{y}
\end{array}\right\}=\frac{N}{R}\left\{\begin{array}{l}
u_{x} \\
u_{y}
\end{array}\right\}+\mu N\left\{\begin{array}{c}
\cos \theta \\
\sin \theta
\end{array}\right\} ; \quad \theta=\frac{F_{f, y}}{F_{f, x}} ; \quad F_{V}=N \quad u_{V} \geq 0 ; \quad F_{V}=0 \quad u_{V}<0
$$

An effective equivalent viscous damping equal to $31.6 \%$ is assumed for the horizontal direction $\left(\xi_{H, e f f}\right)$, neglecting damping in the vertical one. As highlighted by experimental studies [10], friction coefficient $(\mu)$ is affected by many parameters: axial load $(N)$, sliding velocity $(v)$, temperature at the sliding interface and the breakaway and stick-slip phases. Two different models are assumed for the CSS bearings: a simplified model (FP1), where axial load $(N)$ and friction coefficient $(\mu)$ are constant; an advanced model (FP2), where variable axial load $(N)$ is combined with variable friction coefficient at breakaway and stick-slip and as function of the sliding velocity, axial pressure and temperature. Dependence of the friction coefficient on the axial load $(N$ ) and sliding velocity $(w)$ is depicted in Fig
proposed by $[11]$, where: $\mu$ st is the static coefficient of fric
friction coefficients at high and low velocity, respectively;
the kinetic friction coefficient with the sliding velocity;
during the transition from the sticking to the sliding phase [

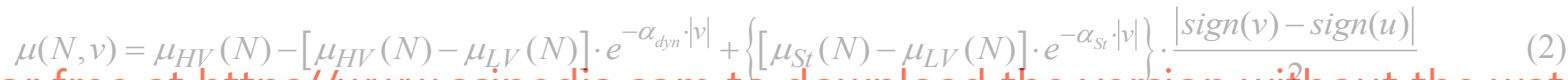

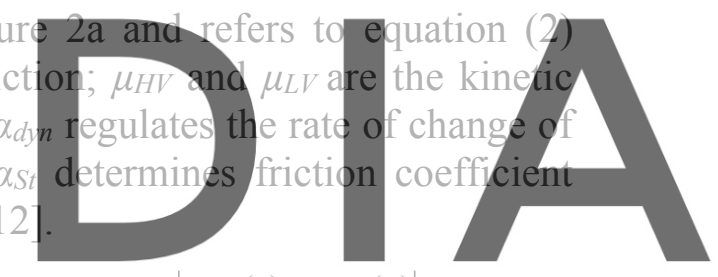
Register for free at https//Www.scipedia.com to download the version without the watermark

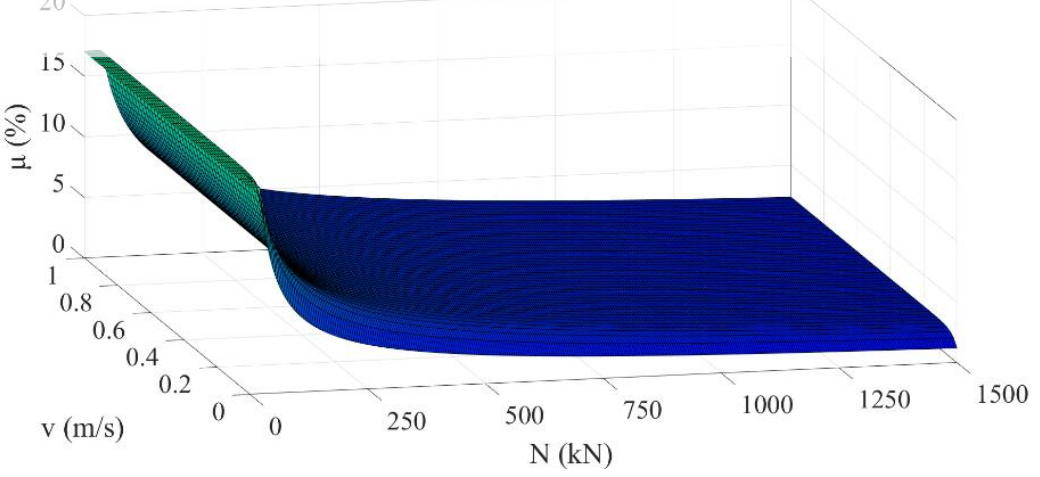

(a)

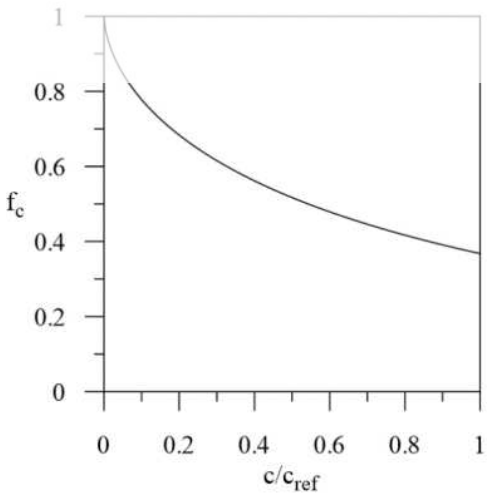

(b)

Figure 2: Variation of the friction coefficient with axial load and sliding velocity (a) and temperature at the sliding surface (b)

The quantities $\mu_{H V}, \mu_{L V}$ and $\mu_{S t}$ are functions of the axial load $(N)$ according to power law expressions (equations (3a,b,c)), where coefficients $A_{H V}, A_{L V}, A_{S t}, n_{H V}, n_{L V}$ and $n_{S t}$ are constants determining the rate of change with the axial load $(N)$. The influence of temperature at the 
sliding interface is taken into account multiplying equation (2) by the degradation function $f_{c}$ (Figure $2 \mathrm{~b}$ ) defined in equation (3d), where $c_{\text {ref }}$ is a parameter that regulates the rate of degradation of friction coefficient, $\gamma$ is a parameter controlling the shape of the function, and $c$ is the degradation variable given by equation (3e) and defined in [11].

$$
\begin{aligned}
& \mu_{H V}(N)=A_{H V} \cdot N^{\left(n_{H V}-1\right)} ; \quad \mu_{L V}(N)=A_{L V} \cdot N^{\left(n_{L V}-1\right)} ; \quad \mu_{S t}(N)=A_{S t} \cdot N^{\left(n_{s t}-1\right)} \\
& f_{c}(c)=e^{-\left(c / c_{r f f}\right)^{\gamma}} ; c(t)=\int_{0}^{t} N(t) \cdot|v(t)|^{2} d t
\end{aligned}
$$

\section{SELECTION OF THE NEAR-FAULT EARTHQUAKES}

In order to assess the effectiveness of concave surface base-isolation system against seismic pounding of irregular adjacent buildings, twenty-one near-fault earthquakes, whose epicentral distance $(A)$ is less than $25 \mathrm{~km}$, are selected from the PEER database [13]. Firstly, an automated algorithm for multicomponent ground motions [14], based on wavelet analysis, is used to identify strong-velocity pulses along the five most probable directions, defining a pulse indicator $(P I)$, as shown in equations $(4 \mathrm{a}, \mathrm{b}, \mathrm{c})$. Selected near-fault ground motions are classified as velocity-pulse, for positive $P I$ values, or no pulse-type (NP), for negative $P I$ ones. Next, an automated algorithm is used to classify velocity-pulse ground motions, rotated in the direction of the strongest pulse, into acceleration pulse-type (AP) and non-acceleration pulse-type (NAP), by identifying potential acceleration impulsivity for each horizontal component [8]. In particular, the pulse-star motions are determined time history is then extr acceleration pulse $(E A P)$ is calculated as report squared acceleration $(C S$
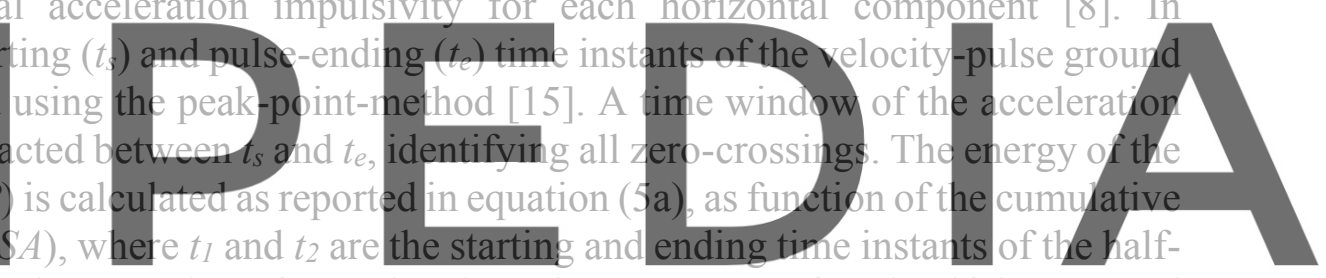

cycle pulse [8]. The maximum value of EAP is adopted as parameter for classifying ground

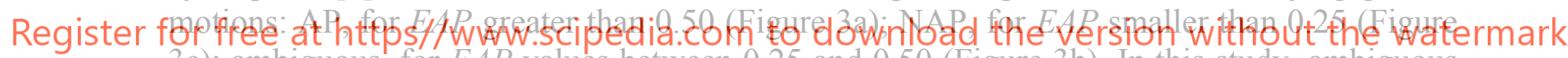
$3 \mathrm{c}$ ); ambiguous, for EAP values between 0.25 and 0.50 (Figure 3b). In this study, ambiguous ground motions are included into the NAP category.

$$
\begin{gathered}
P I=9.384(0.76-P C-0.0616 P G V)\left(P C+6.914 \cdot 10^{-4} P G V-1.072\right)-6.179 \\
P C=0.63\left(\frac{P G V_{\text {residual }} \text { record }}{P G V_{\text {original record }}}\right)+0.777\left(\frac{C S V\left(t_{f}\right)_{\text {residual }} \text { record }}{C S V\left(t_{f}\right)_{\text {original record }}}\right) ; \quad C S V\left(t_{f}\right)=\int_{0}^{t_{f}} v^{2}(\tau) d \tau \\
E A P=C S A\left(t_{2}\right)-C S A\left(t_{1}\right)=\frac{\int_{t_{s}}^{t_{2}} a^{2}(\tau) d \tau}{\int_{t_{s}}^{t_{e}} a^{2}(\tau) d \tau \int_{t_{s}}^{t_{l}} a^{2}(\tau) d \tau} ; \quad \int_{t_{s}}^{t_{e}} a^{2}(\tau) d \tau
\end{gathered}
$$

Each set of ground motions is scaled in line with the current Italian Standard [6], in order to match the design spectrum at the CP limit state. Specifically, the acceleration response spectrum of each earthquake is calculated by taking the square root of the sum of the squares of the 5\%damped spectrum of each component (equation 5b). Then, the SRSS mean spectrum is obtained as the average over the seven SRSS spectra previously defined. The mean SRSS spectrum is scaled by applying a scale factor $(S F)$ for each ground motion, so that it is not lower than the 
$5 \%$-damped elastic design spectrum amplified by 1.3 [6], in the range of vibration period $T_{\min }$ $(=0.15 \mathrm{~s})-T_{\max }\left(=1.2 T_{\text {iso }}=3.72 \mathrm{~s}\right)$. As the lower limit (i.e. $\left.0.15 \mathrm{~s}\right)$ prescribed by Italian Standard [6] is quite far from the isolation period $\left(T_{i s o}=3.1 \mathrm{~s}\right)$, lower limit imposed by EC8 [16] is used for spectral matching $\left(T_{\min }=0.2 T_{i s o}=0.62 \mathrm{~s}\right)$.

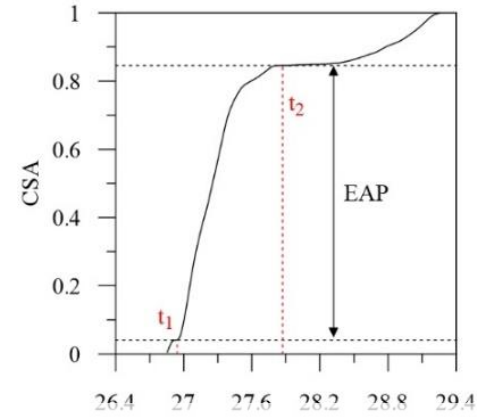

(a) Denali EQ (USA, 2002)

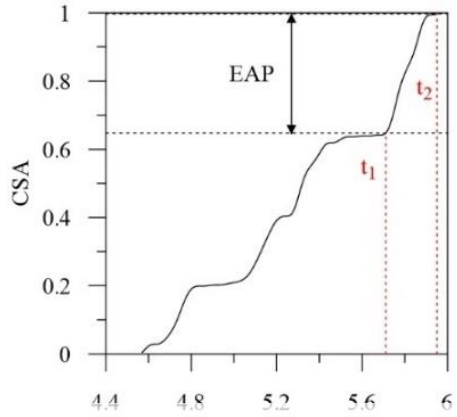

(b) Kobe EQ (Japan, 1995)

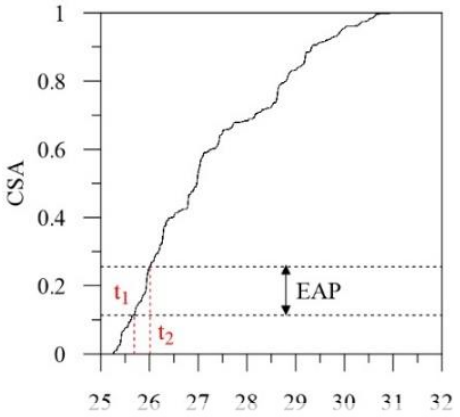

(c) Darfield EQ (New Zealand, 2010)

Figure 3: Example of different typologies of near-fault earthquakes: (a) acceleration pulse, (b) ambiguous, (c) non-acceleration pulse

Table 2: NP near-fault earthquakes (PEER database [13])

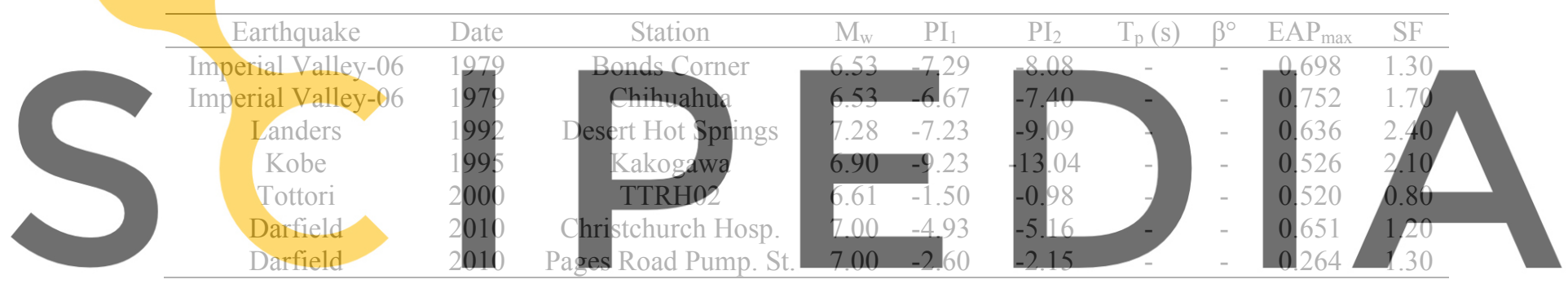

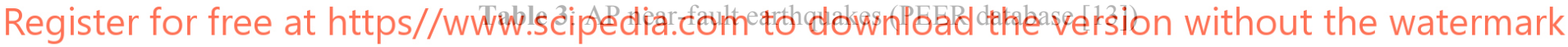

\begin{tabular}{cccccccccc}
\hline Earthquake & Date & Station & $\mathrm{M}_{\mathrm{W}}$ & $\mathrm{PI}_{1}$ & $\mathrm{PI}_{2}$ & $\mathrm{~T}_{\mathrm{p}}(\mathrm{s})$ & $\beta^{\circ}$ & $\mathrm{EAP}_{\max }$ & $\mathrm{SF}$ \\
\hline Imperial Valley-06 & 1979 & $\mathrm{EC}-$ Mel. Geot. Array & 6.53 & 33.26 & 25.36 & 3.42 & 59 & 0.504 & 0.79 \\
Superstition Hills-02 & 1987 & Parachute Test Site & 6.54 & 31.44 & 22.28 & 2.39 & 242 & 0.530 & 0.72 \\
Erzincan & 1992 & Erzincan & 6.69 & 26.17 & 18.49 & 2.66 & 21 & 0.625 & 0.74 \\
Kobe & 1995 & Port Island (0 m) & 6.90 & 11.47 & 5.39 & 2.83 & 332 & 0.729 & 0.60 \\
Denali & 2002 & TAPS Pump St. \#10 & 7.90 & 16.62 & 8.93 & 3.23 & 56 & 0.801 & 0.60 \\
Darfield & 2010 & HORC & 7.00 & 2.96 & 0.97 & 9.92 & 16 & 0.545 & 0.66 \\
Mayor-Cucapah & 2010 & Westside El. School & 7.20 & 3.04 & 5.50 & 7.98 & 311 & 0.537 & 1.35 \\
\hline
\end{tabular}

Table 4: NAP near-fault earthquakes (PEER database [13])

\begin{tabular}{cccccccccc}
\hline Earthquake & Date & Station & $\mathrm{M}_{\mathrm{w}}$ & $\mathrm{PI}_{1}$ & $\mathrm{PI}_{2}$ & $\mathrm{~T}_{\mathrm{p}}(\mathrm{s})$ & $\beta^{\circ}$ & $\mathrm{EAP}_{\max }$ & $\mathrm{SF}$ \\
\hline Imperial Valley-06 & 1979 & EC Array \#6 & 6.53 & 25.50 & 22.46 & 4.13 & 228 & 0.374 & 0.90 \\
Imperial Valley-06 & 1979 & EC Diff. Array & 6.53 & 7.45 & 10.72 & 6.27 & 253 & 0.353 & 1.30 \\
Kobe & 1995 & Takarazuka & 6.90 & 6.62 & 6.62 & 1.81 & 301 & 0.428 & 1.00 \\
Kocaeli & 1999 & Yarimca & 7.51 & 22.95 & 22.95 & 5.31 & 25 & 0.405 & 1.00 \\
Duzce & 1999 & Duzce & 7.14 & 11.20 & 11.20 & 6.88 & 131 & 0.286 & 1.00 \\
Darfield & 2010 & DSLC & 7.00 & 14.21 & 20.19 & 7.83 & 44 & 0.142 & 1.30 \\
Darfield & 2010 & TPLC & 7.00 & 4.71 & 6.33 & 7.88 & 354 & 0.157 & 1.20 \\
\hline
\end{tabular}


Main properties of the twenty-one earthquakes, divided into three set of seven earthquakes, are reported in Tables 2, 3 and 4 for non-pulse (NP), AP and NAP categories, respectively. In particular, $P I$ for the two strongest potential velocity pulses $\left(P I_{1}\right.$ and $\left.P I_{2}\right)$ are reported, together with the pulse period $\left(T_{p}\right)$, the orientation of the strongest pulse counterclockwise with respect to east $(\beta)$, the maximum $E A P$ between the two horizontal components $\left(E A P_{\max }\right)$, and the scale factor $(S F)$. Results of the scaling procedure are also reported in Figure 4, with respect to the three typologies of near-fault earthquakes described above, in terms of spectral acceleration (Figure 4a,b,c) and displacement (Figure 4d,e,f). In particular, design spectrum of the Italian seismic code [6] at the CP limit state (solid black line) is reported together with the upper $(+30 \%)$ and lower $(-10 \%)$ bounds thresholds (dashed black lines). The mean SRSS spectrum (blu line) and the mean spectrum (red line) of the fourteen scaled components of the seven ground motions are also shown. As can be observed, spectral matching is obtained for both acceleration and displacement SRSS mean spectra, when the range $T_{\min }-T_{\max }$ is considered for vibration periods.

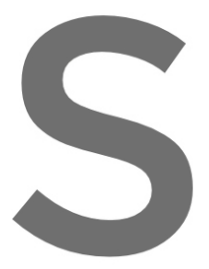

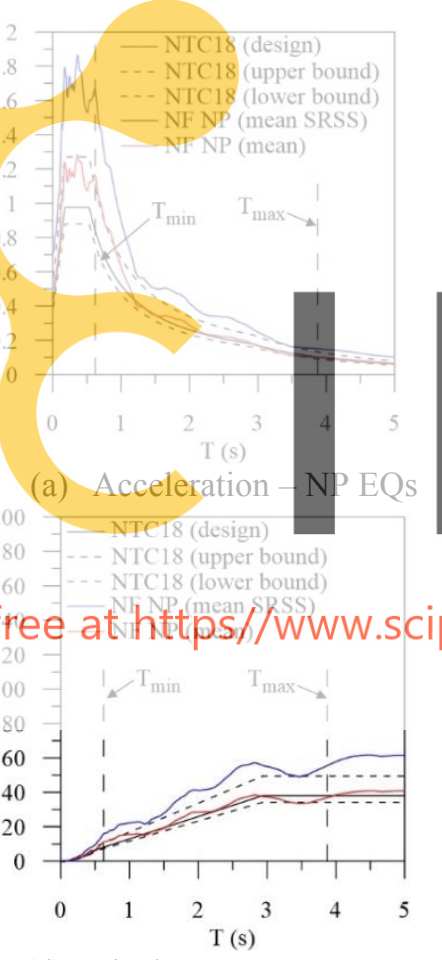

(d) Displacement - NP EQs
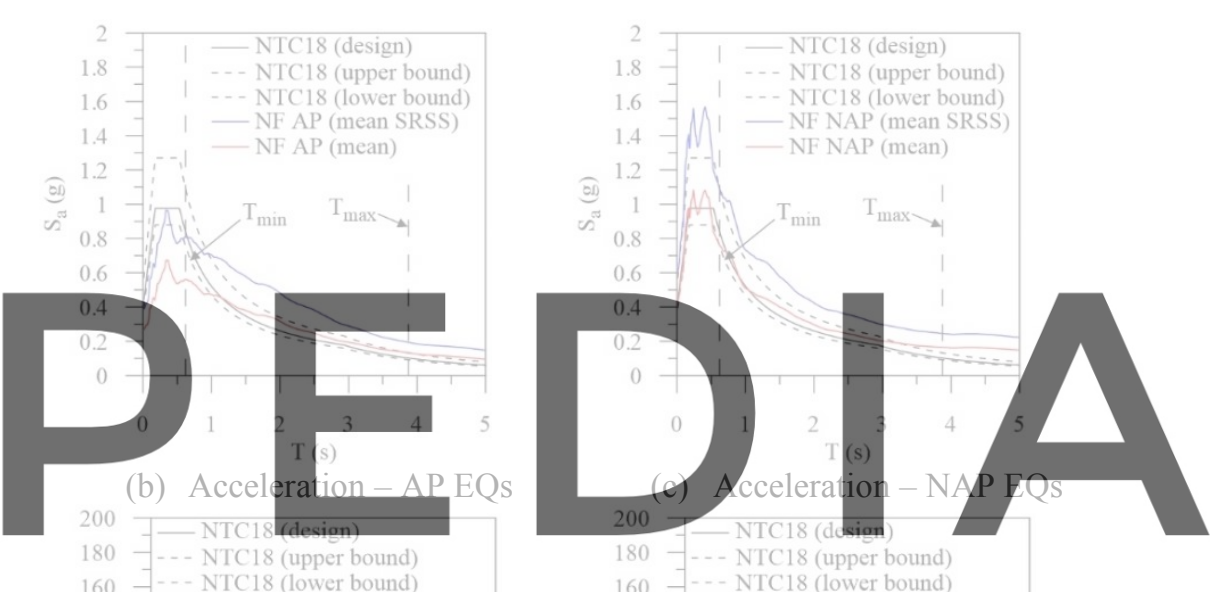

Register for free atihttps;//Www.scipedia.com to download the version without the watermark

Figure 4: Comparison between elastic design spectrum and mean elastic spectrum of scaled ground motions, in terms of acceleration $(\mathrm{a}, \mathrm{b}, \mathrm{c})$ and displacement $(\mathrm{d}, \mathrm{e}, \mathrm{f})$

\section{NUMERICAL RESULTS}

Nonlinear dynamic analysis of the in-plan irregular r.c. framed structure described in Section 2, before (i.e. fixed-base, depicted in black in Figure 5) and after (i.e. base-isolated, depicted in red in Figure 5) retrofitting with CSS bearings, is carried out considering three typologies of near-fault earthquakes presented in Section 3. Structural pounding incidence between fixedbase and base-isolated buildings is evaluated referring to adjacent configurations forming $\mathrm{T}$ - 
and C-shaped plans (Figure 5). A computer code [7] is modified in order to compare two nonlinear models of the CSS bearings, which are designed with the same radius of curvature $R$, equal to $4.5 \mathrm{~m}$, and friction coefficient at high velocity $\mu_{H V}$, equal to $4.5 \%$.

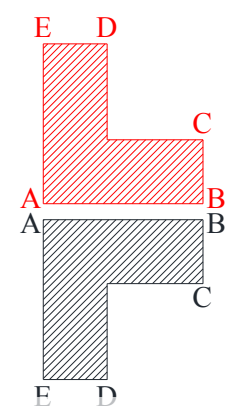

(a) T1 configuration

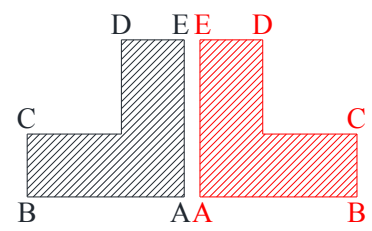

(b) $\mathrm{T} 2$ configuration

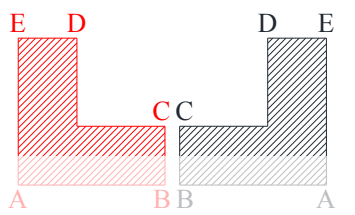

(d) C1 configuration

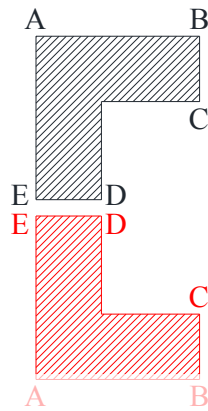

(c) C2 configuration

Figure 5: In-plan configurations for adjacent fixed-base (black) and base-isolated (red) buildings

A simplified model of a CSSB (FP1), where axial load and friction coefficient are constant, and an advanced one (FP2), with variable axial load combined with friction coefficient variable at breakaway and stick-slip [12] and function of sliding velocity, axial pressure and temperature

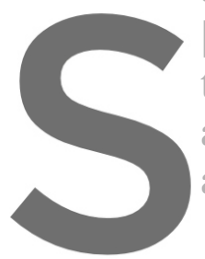
[11], are implemented
the values assumed in
and $2 A_{H V}[17]$, respect
assumed equal to 17.0
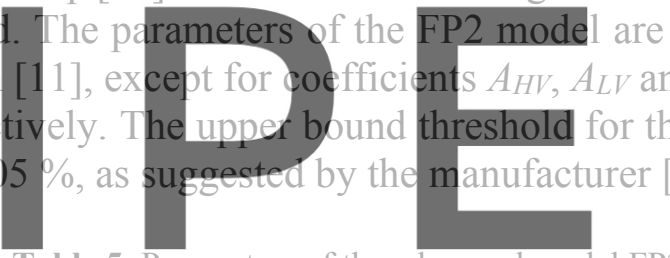

Table 5: Parameters of the advanced model FP2 for CSSBs
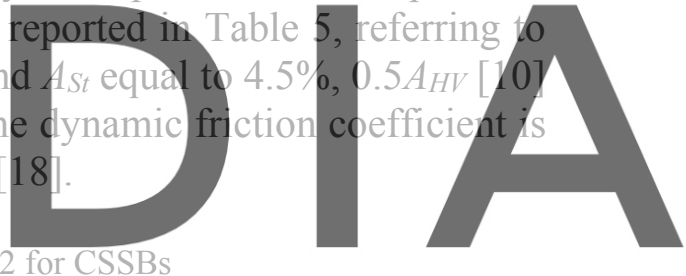

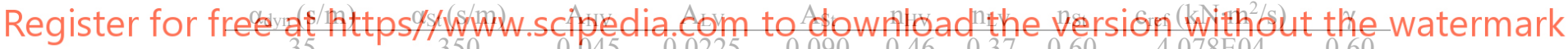

A lumped plasticity model describes the nonlinear behaviour at the end sections of r.c. frame members, where a flat surface axial load-biaxial bending moment elastic domain is adopted [7]. Shear deformation of r.c. frame members is neglected, while axial and flexural stiffness are evaluated considering a Young modulus equal to $31500 \mathrm{MPa}$. Mass and stiffness proportional damping is assumed, with a viscous damping ratio equal to $1 \%$ and $5 \%$ for base-isolated and fixed-base structures, respectively.

Mean values of the relative displacement $(g)$ between fixed-base and base-isolated buildings, forming T- and C-shaped plans, are reported in Figure 6, considering the NP, AP and NAP typologies of near-fault earthquakes. When the FP1 model is adopted for CSS bearings (Figure $6 \mathrm{a}, \mathrm{b}, \mathrm{c})$, an almost constant trend along the building height of the four in-plan configurations is evident for NP near-fault earthquakes (Figure 6a), with values ranging from about $12 \mathrm{~cm}$ (level 2 of $\mathrm{C} 2$ ) to $20 \mathrm{~cm}$ (roof level of T1). Relative displacement increases for AP near-fault earthquakes (Figure 6b), with values ranging from about $18 \mathrm{~cm}$ (isolation level of C2) to $35 \mathrm{~cm}$ (roof level of T2), with an increasing tendency along the height for the T2 configuration. 


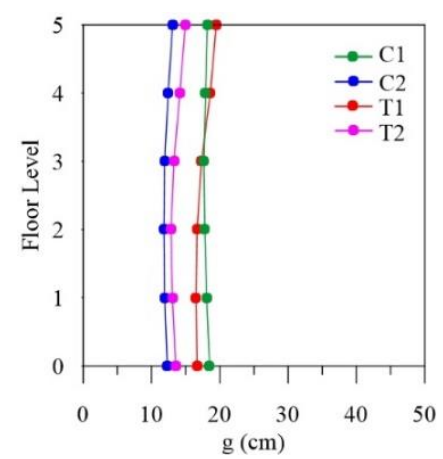

(a) FP1 Model - NP EQs

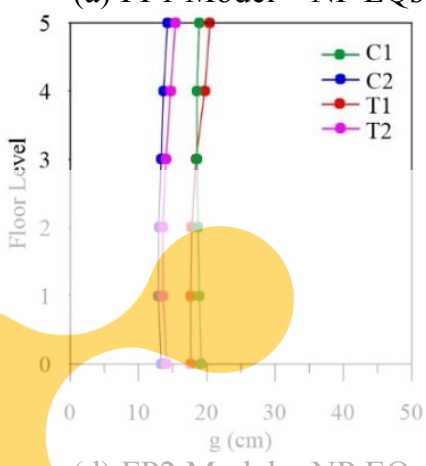

(d) FP2 Model - NP EQs

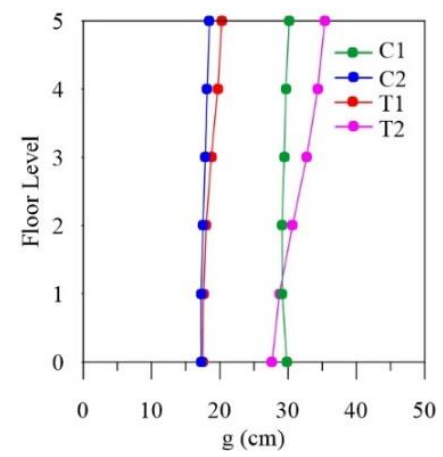

(b) FP1 Model - AP EQs

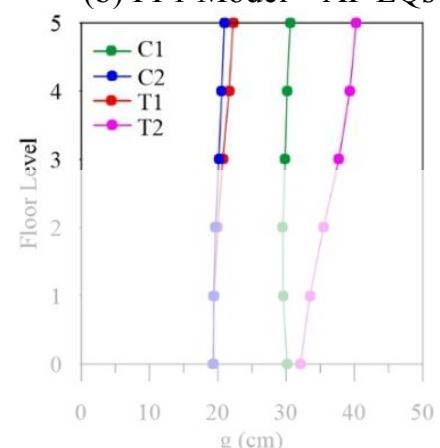

(e) FP2 Model - AP EQs

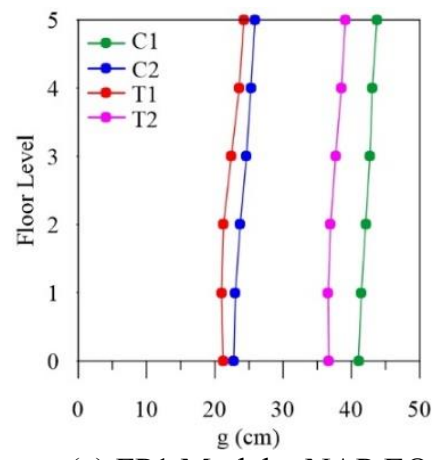

(c) FP1 Model - NAP EQs

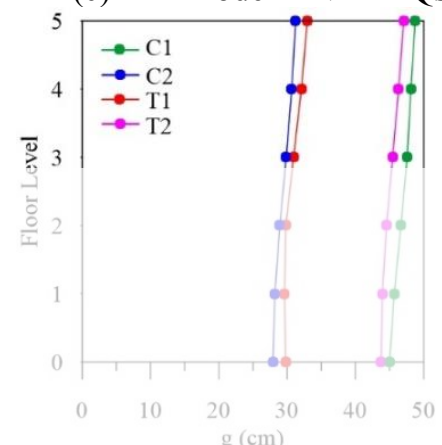

(f) FP2 Model - NAP EQs

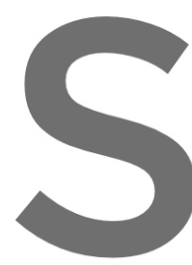

Figure 6: Mean values of $\mathrm{r}$
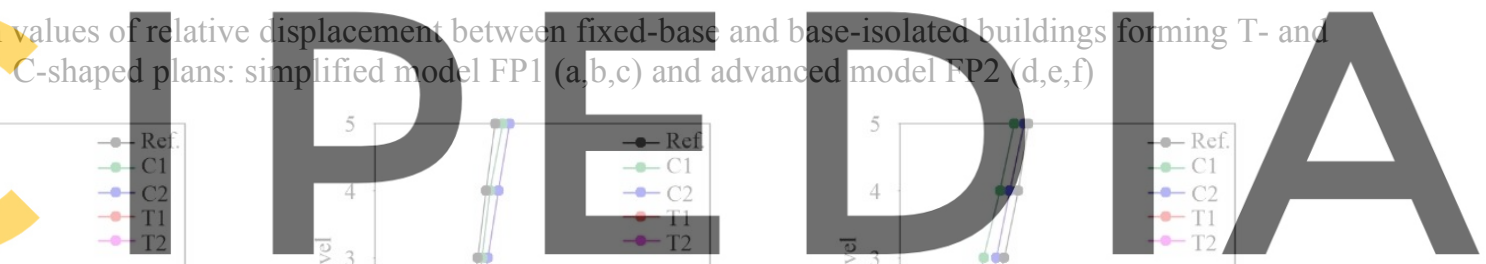

Register for free at https//www.scipedia.com to download the version without the watermark

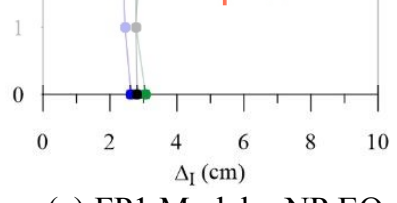

(a) FP1 Model - NP EQs

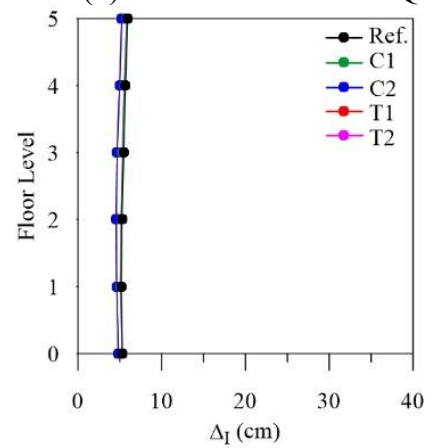

(d) FP2 Model - NP EQs

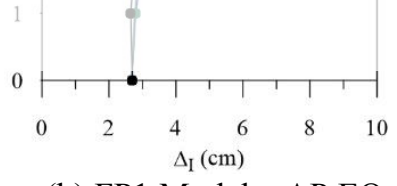

(b) FP1 Model - AP EQs

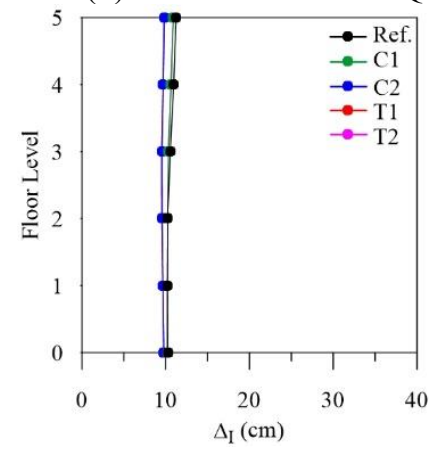

(e) FP2 Model - AP EQs

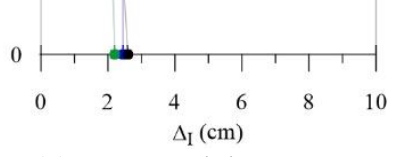

(c) FP1 Model - NAP EQs

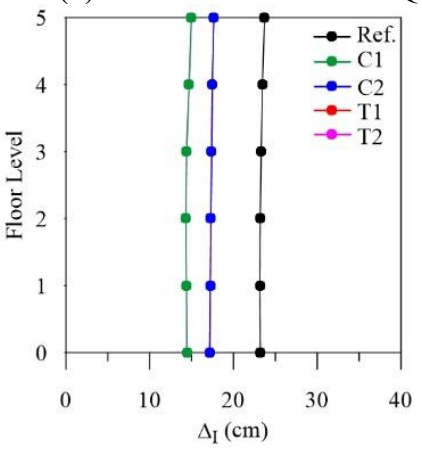

(f) FP2 Model - NAP EQs

Figure 7: Mean values of torsional response of base-isolated buildings forming $\mathrm{T}$ - and $\mathrm{C}$-shaped plans: simplified model FP1 $(\mathrm{a}, \mathrm{b}, \mathrm{c})$ and advanced model FP2 (d,e,f) 
The greatest values of $g$ are observed for NAP near-fault earthquakes (Figure 6c). In this case, an almost constant trend along the height is confirmed, although significant differences can be observed with reference to the in-plan configurations. Specifically, mean value of the relative displacement ranges from a minimum of about $22 \mathrm{~cm}$ (isolation level of C2) to a maximum of about $43 \mathrm{~cm}$ (roof level of C1). Moreover, mean values of $g$ for the FP2 model have quite similar trends to those obtained when the FP1 model is adopted (Figure 6d). Similar results for T- and C-shaped plans are recorded for NP near-fault earthquakes (Figure 6d), while appreciable differences appear when AP near-fault motions are analysed (Figure 6e); an increment of about $7 \mathrm{~cm}$ be found at all levels of the T2 configuration, in comparison to the results for FP1 model (Figure 6b). For the case of NAP earthquakes, a significant increment is highlighted (Figure 6f), with respect to the results obtained for FP1 model (Figure 6c). A strong influence of the in-plan configuration is evident, with mean values ranging from about $30 \mathrm{~cm}$ (for $\mathrm{C} 2$ and $\mathrm{T} 1$ at isolation level) to about $50 \mathrm{~cm}$ (for $\mathrm{C} 1$ and $\mathrm{T} 2$ at roof level).

Afterwards, mean values of torsional response $\left(\Delta_{I}\right)$ of the base-isolated buildings, calculated as the absolute value of the difference between displacements of nodes A and B along the $\mathrm{Y}$ direction (Figure 5), are shown in Figure 7, with reference to the FP1 (Figure 7a,b,c) and FP2 (Figure 7d,e,f) models. Very low values of $\Delta_{I}$ are recorded in the case of FP1 model and NP earthquakes (Figure 7a), ranging from $2 \mathrm{~cm}$ (level 2 of C2) to $4 \mathrm{~cm}$ (roof level of C1), with a negligible influence of the in-plan configuration. A similar trend is evident for the AP (Figure $7 \mathrm{~b}$ ) and NAP (Figure 7c) earthquakes, with small variations along the height and with respect to the in-plan configuration when the EP1 model is considered. However, notable values of in plan torsion are obtaine AP (Figure 7e) and $N$ resulted for NP earth evident for AP and NAP earthquakes (Figure respectively. Slight values of in-plan torsion ar
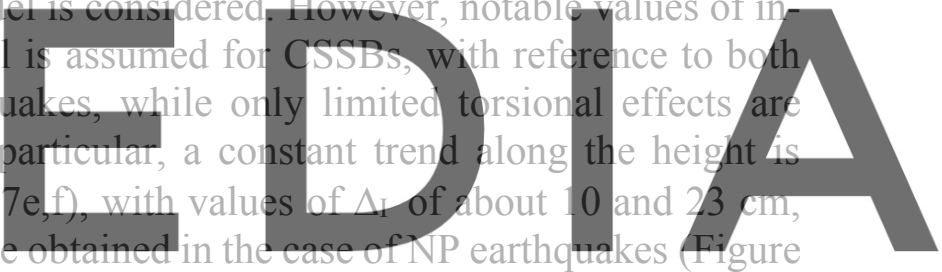

$7 \mathrm{~d}$ ), with constant $\Delta_{\mathrm{I}}$ of about $5 \mathrm{~cm}$ at all levels. Influence of the in-plan configuration can be

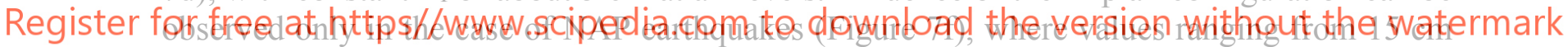

(C1) to $23 \mathrm{~cm}$ (red configuration in Figure 5) are recorded.

The influence of the nonlinear modelling of CSSBs is also evaluated with reference to the displacements $(d)$ of the corner joints at the isolation level (Figure 8), for the reference configuration, along the two principal in-plan directions and for a near-fault earthquake representative of each typology. In particular, displacements of corner joints at instant of time of maximum torsion are reported in Figure 8a (FP1) and Figure 8b (FP2) for the NP Imperial Valley EQ (California, 1979). As can be observed, displacements of corner joints A and B, along the Y direction, are similar for the FP1 model (Figure 8a), while increasing difference results when FP2 model is assumed (Figure 8b). Notable difference between displacement of corner joints $\mathrm{A}$ and $\mathrm{B}$, along the $\mathrm{Y}$ direction, is also evident in Figure 8d, corresponding to the AP Denali EQ (Alaska, 2002) and FP2 model. On the contrary, differences disappear in Figure $8 \mathrm{c}$, where FP1 model is considered for the same earthquake. The greatest differences are obtained for the NAP Kobe EQ (Japan, 1995) and FP2 model, with bearings A and B that undergo very different displacements along the $\mathrm{Y}$ direction, producing high values of torsion at the isolation level. Finally, only slight differences are obtained when the FP1 model is assumed for the same earthquake (Figure 8e). 


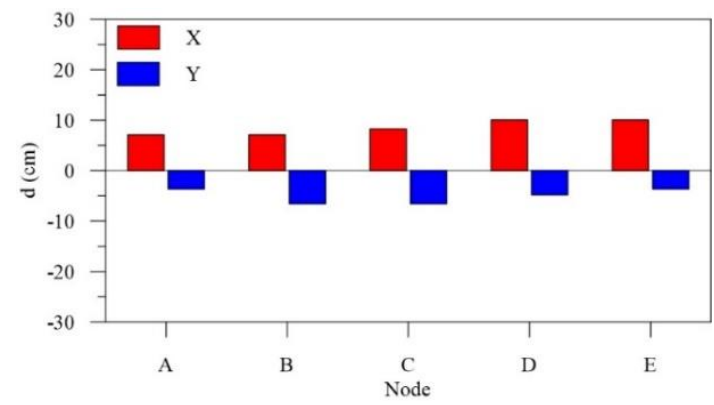

(a) FP1 Model - NP earthquake

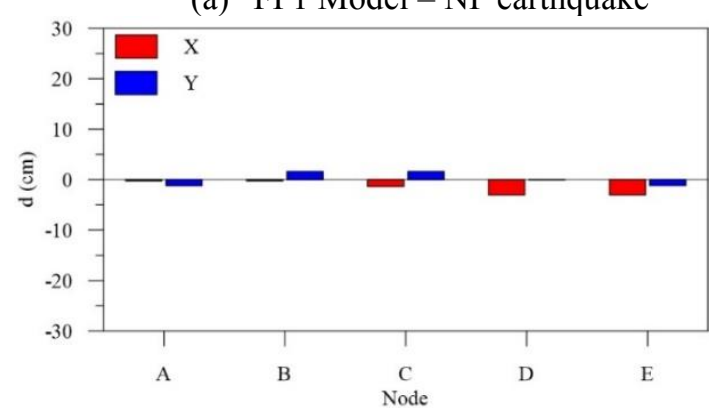

(c) FP1 Model - AP earthquake

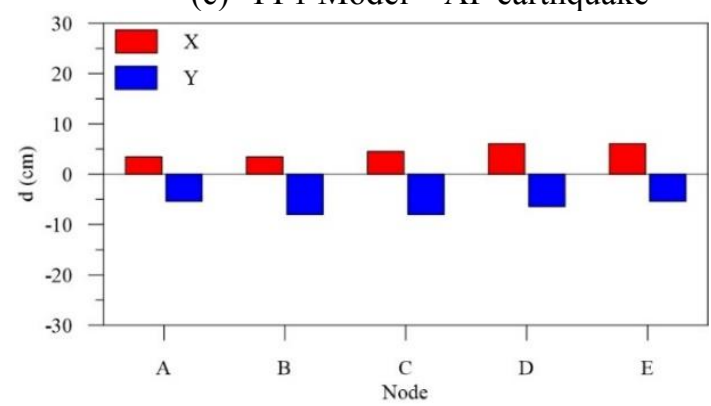

(e) FP1 Model - NAP earthquake

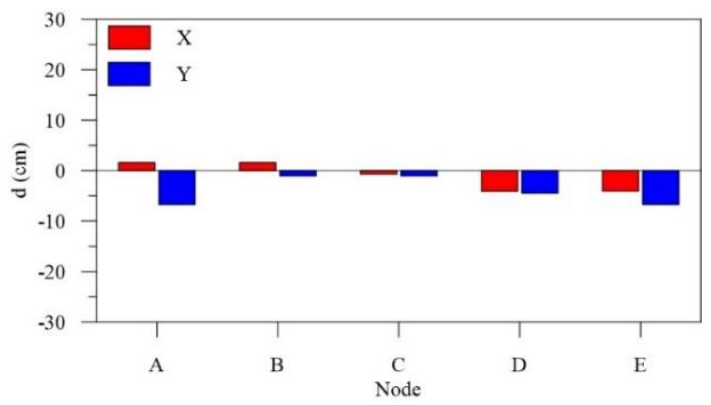

(b) FP2 Model - NP earthquake

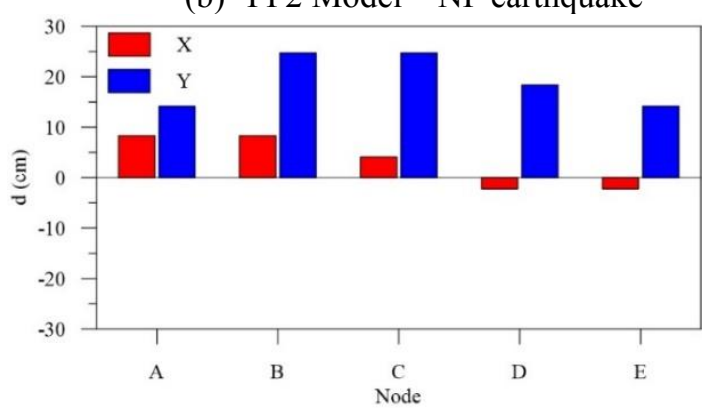

(d) FP2 Model - AP earthquake

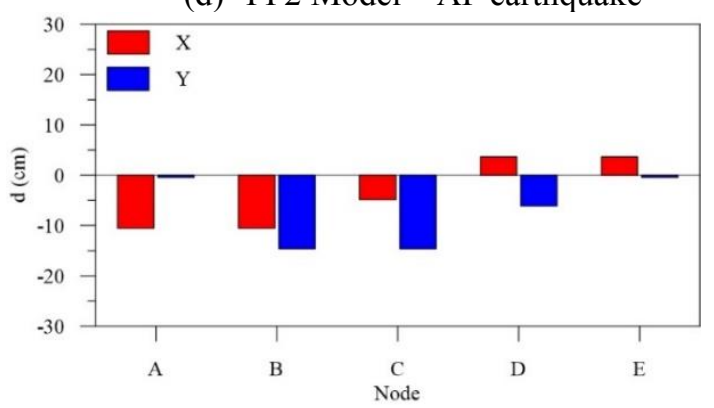

(f) FP2 Model - NAP earthquake

Figure 8: Displacements of the corner joints at the isolation level and instant of time of maximum torsion: Imperial Valley EQ, 1979 (a,b); Denali EQ, 2002 (c,d); Kobe EQ, 1995 (e,f)

\section{CONCLUSIONS}

Structural pounding is analysed with reference to five-storey r.c. framed structures with an L-shaped plan placed adjacent to form T- and C-shaped configurations. Relative displacement between the fixed-base (original) and base-isolated (retrofitted with CSS bearings) structures is evaluated, considering the facing sides of the perimeter. Non-pulse-type and pulse-type ground motions are selected, classifying the latter as acceleration pulse (AP) and non-acceleration pulse (NAP). Two models are assumed for the CSSBs: i.e. FP1, with constant axial load and friction coefficient; FP2, with variable axial load and dynamic friction coefficient. Concluding briefly on the results:

- simplified model (FP1) underestimates pounding effects between adjacent buildings; same consideration can be drawn about in-plan torsional response;

- advanced model (FP2) predicts pounding effect between adjacent buildings greater than the simplified one; in addition, it highlights the presence of notable in-plan torsion at all levels (especially at the isolation one); 
- FP1 and FP2 models lead to comparable results in terms of pounding effects for NP nearfault earthquakes, with a notable increase of the in-plan torsional response when FP2 model is assumed; significant increase of pounding effect and torsional demand is obtained for AP and especially NAP near-fault earthquakes.

\section{REFERENCES}

[1] Mazza, F. and Mazza, M. Nonlinear seismic analysis of irregular r.c. framed buildings baseisolated with friction pendulum system under near-fault excitations. Soil Dyn Earthq Eng (2016) 90:299-312.

[2] Mazza, F. and Vulcano, A. Effects of near-fault ground motions on the nonlinear dynamic response of base-isolated r.c. framed buildings. Earthq Eng Struct Dyn (2012) 41:211-232.

[3] Kalkan, E. and Kunnath, S.K. Relevance of absolute and relative energy content in seismic evaluation of structures. Adv Struct Eng (2008) 11(1):17-43.

[4] Pan, T.C. and Kelly, J.M. Seismic response of torsionally coupled base isolated structures. Earthq Eng Struct Dyn (1983) 11(6):749-770.

[5] DM96. Norme Tecniche per le costruzioni in zone sismiche. Ministero dei Lavori Pubblici, D.M. 16-01-1996, (1996).

[6] NTC18. Norme Tecniche per le Costruzioni. Ministero delle Infrastrutture, D.M. 17-012018, (2018).

[7] Mazza, F. and Mazza, M. Nonlinear Modeling and Analysis of R.C. Framed Buildings Located in a Near-Fault Area. Open Constr Build Technol J (2012) 6:346-354.

[8] Chang, Z., De Luca, F., Goda, K. Automated classification of near-fault acceleration pulses using wavelet packets. Computer-Aided Civil and Infrastructure Engineering (2019) 34:569-585.

[9] Mazza, F. Seismic demand of base-isolated irregular structures subjected to pulse-type earthquakes. Soil Dyn Earthq Eng (2018) 108:111-129.

[10] Kumar, M., Whittaker, A.S., Constantinou, M.C. Characterizing friction in sliding isolation bearings. Earthq Eng Struct Dyn (2014) 44(9):1409-1425.

[11] Gandelli, E., Penati, M., Quaglini, V., Lomiento, G., Miglio, E., Benzoni, G.M. A novel OpenSees element for single curved surface sliding isolators. Soil Dyn Earthq Eng (2019) 119:433-453.

[12] Quaglini, V., Bocciarelli, M., Gandelli, E., Dubini, P. Numerical Assessment of Frictional Heating in Sliding Bearings for Seismic Isolation. J Earthq Eng (2014) 18(8):1198-1216.

[13] PEER. Pacific Earthquake Engineering Research Center database. (2014).

[14] Shahi, S.K. and Baker, J.W. An efficient algorithm to identify strong-velocity pulses in multicomponent ground motions. Bull Seismol Soc Am (2014) 104(5):2456-2466.

[15] Zhai, C., Chang, Z., Li, S., Chen, Z., Xie, L. Quantitative identification of near-fault pulse-type ground motions based on energy. Bull Seismol Soc Am (2013) 103(5):2591-2603.

[16] EC8. Design of structures for earthquake resistance - Part 1: General rules, seismic actions and rules for buildings. C.E.N. European Committee for Standardization, (2004).

[17] Fagà, E., Ceresa, P., Nascimbene, R., Moratti, M., Pavese, A. Modelling curved surface sliding bearings with bilinear constitutive law: effects on the response of seismically isolated buildings. Mater Struct (2015) 49: 2179-2196.

[18] FIP Industriale S.p.A. Catalogo S04: isolatori a superficie curva. Padova, (2013). 